\title{
Cultivation Mode for Application-oriented Talents on Numerical Control Technology
}

\author{
Dongfang $\mathrm{Hu}^{1, \mathrm{a}^{\star}}$ and Ruonan Lei $\mathrm{i}^{2, \mathrm{~b}}$ \\ ${ }^{1}$ School of Mechatronics Engineering, Henan University of Science and Technology, Luoyang \\ 471003, China \\ ahdf@haust.edu.cn, ${ }^{\mathrm{b}} 18736289291 @ 163 . c o m$
}

\begin{abstract}
Keywords: Numerical control technology; Application-oriented talents; Cultivation mode; Training targets; Hierarchical division
\end{abstract}

\begin{abstract}
With the continuous development of economy in China, numerical control technology has been rapid development. At present, the demands of qualified personnel on numerical control technology are great, the popularization of numerical control technology is increasingly fierce. Furthermore, Ministry of Education explicitly identified that numerical control technology is one of the urgent-needed professionals in our country, thus, it is of great significance to cultivate application-oriented talents on numerical control technology. Considering the present situation of cultivation mode in universities and the level of kinds of universities, three training targets for application-oriented talents on numerical control technology, and hierarchical division of training methods were proposed, the demands of enterprises on NC talents, and the orientation of training NC talents in colleges and universities, the specific characteristics of application-oriented numerical control talents were analyzed. In particular, the cultivation mode for application-oriented talents on numerical control technology of ordinary colleges and universities was discussed.
\end{abstract}

\section{Introduction}

$\mathrm{NC}$ technology is one of the key technology of modern manufacturing [1,2], and its theory and technology has made a great development. It has become a trend in the development of manufacturing technology [3], the advanced manufacturing technology with NC technology-based to quickly replace the traditional mechanical manufacturing technology to improve the adaptability and competitiveness in such market. Thus it is necessary for the developed countries to accelerate economic development, and to improve the comprehensive competitiveness by developing advanced manufacturing technology. According to investigation research and analysis of the Ministry of Education [4], in the next few years, personnel from research development to operation of the NC technology are needed urgently in China. How to make the NC talents cultivated in colleges and universities to adapt to the fast changing times and continuous improvement technology, has become a primary consideration for colleges and universities [5].

The universities should undertake the duty for cultivating personnel from research development to practical application of all levels to some extent. Our NC personnel training model is relatively backward and with low grade, so it cannot fully meet the actual needs of enterprises [6], the main reason is that the current concept of higher education is backward, and its positioning is not accurate, which largely affected the competitiveness of China's numerical control. Therefore, according to the teaching resources at all levels of colleges and universities, teaching conditions, funding, different teachers and other factors, it is necessary to assign different targeting position for diversity of university in the aspect of NC personnel cultivation. The key universities should be located in training scientific research talents [7], the ordinary colleges should be positioned in training applied talents [8], and the vocational colleges should be located in training application of operational personnel [9]. Such positioning division could improve the relevance of NC personnel training and adapt to talent goals of social [10]. The training method which is cultivate application-oriented talents on numerical control technology has been discussed in this paper. 


\section{The Hierarchical Division of Cultivation Methods in Colleges and Universities}

In recent years, the higher education is developing rapidly, it has been from elite education to mass education gradually, the levels and types of higher education has been greatly developed. But in terms of NC personnel training, college cultivation and business needs have not yet fully achieved harmony development, and the division for numerical control personnel training level is not very clear, there is no significant difference in training methods especially among undergraduate school, so how to achieve the target to meet the needs of enterprises is still a serious problem.

The Present Situation of Cultivation Mode in University and the Demands of Enterprises. Currently, the NC personnel of company mainly from two cultivating channels, the school and enterprises. NC personnel of school can be divided into two categories, one kind is being trained by the undergraduate level. It focuses on academic and theoretical cultivation, emphasis on the dissemination of CNC knowledge, and the leaning of theoretical knowledge, but with poor hands, this is a traditional training model. This type of academic talent has been significantly in excess of the current job market; The other kind comes from the college or vocational school, such people have some basic theoretical knowledge and practical ability to easily and quickly adapt to the ordinary NC jobs, its job market is pretty good, but with the continuous development of NC technology to the functional complex and high-tech areas, such talents have been gradually under shift. These two types are lack of experience in technology companies due to school teaching conditions, so these people is more and more difficult to meet the requirements of the enterprise. However, the people who are trained in company, they can engage in business from existing over-machining or maintenance staff, be selected to participate in a number of numerical control technology of different levels. After the short-term job training, these people can get in position. Their advantage is that such enterprises have practical experience and technological background, while the disadvantage is the original part of the knowledge is outdated, especially in computer technology and computer numerical control system, their self-learning ability is too limited to keep up with modern technology, the space for development is limited. Those people are also too difficult to become advanced application talents.

At present, Chinese manufacturing enterprises ongoing technical updates, from digestion to the introduction of foreign high-end NC equipment products to the its own degree of domestic production, technological content and device complexity are increasing continuous, companies use NC professional personnel already clearly have the specialized and hierarchical characteristics. Corporation demand for NC personnel changed in nature, from seeking the number to seek high-quality. Operating NC equipment easily has not become a major problem for business anymore, but to learn to master the key equipment. Because such devices require more comprehensive knowledge and skills quality, these talents are the desired people for the businesses.

The Hierarchical Division of Cultivation Methods in Colleges and Universities. Currently, the NC talents mainly from two cultivating channels, one is trained in the school, where they are divided into two categories, one of them is being trained by the undergraduate level. It is focus on academic and theoretical cultivation and NC knowledge spreading and systematic theoretical knowledge, but its manipulative ability is bad, this is a traditional training model. This type of academic talent has been significantly in excess of the current job market; the other kind of talents from the college and vocational school training, such people have some basic theoretical knowledge and practical ability to easily and quickly adapt to the ordinary $\mathrm{NC}$ jobs, its job market is pretty good, but with the continuous development of NC technology to the functional complex and high-tech areas, such talent level has been gradually under shifting; Above these two types of personnel training due to school teaching conditions, lack of experience in technology companies, so those people are more and more difficult to meet the requirements of the enterprise. The second kinds of people are being trained by the company, who are engaged in business from existing over-machining or maintenance staff. Those people who being selected to participate in a number of numerical control technology of different levels. After the short-term job training, these people get in position. Their advantages is that such people have practical experiences and technological background. While the disadvantage is the original part of the knowledge is outdated, especially in computer technology and computer numerical control system. Their 
self-learning ability is too limited to keep up with modern technology, the space for development is limited. So those person is also too difficult to become advanced application talents.

At present, Chinese manufacturing enterprises ongoing technical updating, from digestion to the introduction of foreign high-end $\mathrm{NC}$ equipment products to its own degree of domestic production, technological content and device complexity are increasingly continuous, the companies already have the specialized and hierarchical characteristics in using NC personnel. Corporation demand for NC personnel have changed in essence. From seeking the number to seeking high-quality. Those people who could easily operate NC equipment has not become a major problem for business anymore, instead of to learn to master the high, refined, sharp, difficult large-scale key equipment. Because such devices require more comprehensive knowledge and skills quality, the talent in such key position is desired by the business in present.

Characteristics of Application Technology Talents in Numerical Control Technology. Applied and technique-type personnel is mainly engaged in formulating NC machining technology program, compiling NC manufacturing program. And these people should be able to manipulate large expensive complex or overseas high precision advanced numerical control equipment to complete NC machining products. Besides, NC machine tools mechanical system structure and electrical construction also should be grasped. Mastering CNC machine tool mechanical and electrical joint adjustment, and can complete the CNC system selection, installation, commissioning and maintenance. Such people are the main force in NC applications in various fields in the future, and they should have the following key features:

First, the high level. Application and technology-type talents are belonged to high level talent, different from the academic talents of key universities, they have strong practical ability to analyze and solve practical problems in production; different from higher vocational education, they have a wide knowledge and high level skills, they are the core competitiveness of enterprises.

Second, professional. It is necessary to have well basis of English and computer for those who in key positions in the NC group work. Those people who could participate in international exchanges and cooperation and with ability to solve practical problems is more likely to become the target executive search firm chase.

Third, multi-aspect. The NC talents with practical skills and base theory. Not only could understand numerical theory, but also could operate complex equipment, meanwhile, easy to adapt to new technologies rapidly.

\section{The Cultivation of Application-oriented Talents on Numerical Control Technology}

Ordinary colleges should thoroughly change the traditional training methods in the application technology talents in NC, updating the ideas, and exploring actively ways to cultivate talents, the following measures can be taken:

Establish a clear training plan for application-oriented talents of numerical control technology. Constructing a reasonable curriculum and teaching content system, conducting necessary replacement of curriculum, reflecting the project-oriented, application-oriented characteristics of the era of education, strengthen the professional targeted courses, so that theory and practice could mutual penetration.

Highlight the application quality cultivating in practical aspects. Practical teaching is an important way and guarantee to cultivate the advanced applied technology talents, the proportion of the experiment should be increased in teaching, the setting of experiment should highlight the characteristics of application, advance, integration, in a variety of practice session the students' initiative to create awareness should be given full inspiration ,the spirit of innovation and ability in practical should also be inspired, walk through the talent-cultivating road which combined research, production and study, strengthening cooperation between enterprise and school, broadening their horizons and some college with good conditions can also extended their classroom teaching to the production line.

Adjust the teaching textbook, teaching staff and other resources. Textbooks should be targeted and practical, which could outstand professional skills of students, focusing on the combination of theory and practice, and emphasize the cultivation of practice and application capabilities. Teachers should be 
equipped with practical experience and good NC professional quality, using advanced teaching methods as much as possible in teaching, making a reasonable use for existing resources under limited capital investment rational, and taking student as main body in teaching.

Strengthen the cultivation of vocational awareness ability. Stimulating students' motivation to learn by using knowledge, ability, quality, cultivate the self-learning ability and the will to learn, recognizing their value in terms of ideology, and cultivate the belief of heart to the development of a numerical technique and strive to be NC application and technology -type talents.

\section{Conclusion}

$\mathrm{NC}$ personnel training face to the needs of the enterprise is the eternal topic for colleges and universities, as the changing of the era for NC personnel requirements, the level and way of NC personnel training should also keep close pace with the times. The school education should teach students to make preparation for the work of the enterprise, not only to ensure the students to establish a good occupation morality, develop a serious working attitude, improve a high work enthusiasm, and cultivate the concept of labor, organization and discipline, so as to accomplish the transformation of their social roles as soon as possible, meanwhile, ordinary colleges and universities should focus on cultivating advanced application-oriented talents of numerical control technology, to meet the business demand for high-level personnel of the $\mathrm{NC}$, and getting a position in the sustainable development of China's NC technology, and to make contributions for sustainable development of numerical control technology in china.

\section{Acknowledgement}

The authors gratefully acknowledge the National Superior Course and Bilingual Teaching Demonstration Course for financial support of this research work and the Project for Education and Teaching Reform of Henan University of Science and Technology (No. 2012N-007).

\section{References}

[1] X.D. Dong, Y. Zhang: New Technology \& New Products of China, Vol. 07(2013), p.142 (In Chinese).

[2] Y.G. Wang: China, Patent CN105931512A. (2016) (In Chinese).

[3] Y.M. Li: Value Engineering Vol. 21(2014), p.48 (In Chinese).

[4] C.D. Guo: Selection and development path of enterprise technology innovation model. (Ph.D., Beijing Institute of Technology, China 2013), p.28 (In Chinese).

[5] Q.Y. Zhao. Research on teaching model of "integration of theory and practice" in NC Specialty of secondary vocational school. (MS., Hebei Normal University, China 2015), p.28 (In Chinese).

[6] S.X. Liu, X.M. Wang. Occupation. Vol. 02(2016), p.45 (In Chinese).

[7] H. Li, X.H. Li: Journal of Chongqing University of Science and Technology. Vol. 08(2008), p. 215 (In Chinese).

[8] Z.J. Qu, R.1. Wang, and S.l. Su: University Education. Vol. 09(2015), p.146 (In Chinese).

[9]F. Cao: Education and Vocation, Vol. 32(2011), p.100 (In Chinese).

[10] Y.H. Ma, Q. Zhang: Information, Business and Management. (Singapore, December 30, 2015). Vol. 49, p.4. 